\title{
The Great Tower Telescope of the Mt. Wilson Solar Observatory
}

\author{
A Description of the World's Largest Reflector
}

By I)r. F. A. Fath, Mt. Wilson Observatory

N 1907 there was erected at Mt. Wilson a tower tele1 seope 60 feet in height for solar work. This instrumen was the first of its kind ever constructed. For this reason it was in a large measure an experiment, but one which proved such a success that, after a year's work Director Hale beran to plan for a much larger on with all the improvements which experience had shown to be desirable.

The result of

this planning

is the great

tower which

is the subject

In such an

instrument the

optical parts

must be solidly

mounted so

that they can-

not be shaken

by the wind

they must not

be sensibly

distorted by

the strong sun-

light falling

on them; the

beam of light

from the sun

must be re-

ceived at as

great an alti-

tude above the

ground a s

possible; the

tower must b

sufficiently

high to per-

use of

lens of great

focal length

so as to give

large image of

the sun when

sch is desired

the auxiliar

must be large

to obtain large

cale photo-

raphs of the

olar spectrum,

etc., and must

be so placed

shall be neither

flexure nor

change of

emperatur

during expos-

ures lasting,

possibly

everal hours.

In order to

simplify mat-

ers let us

consider the

tower tele-

seope as mere-

ly a telescope

of the usual

type but of

very grea

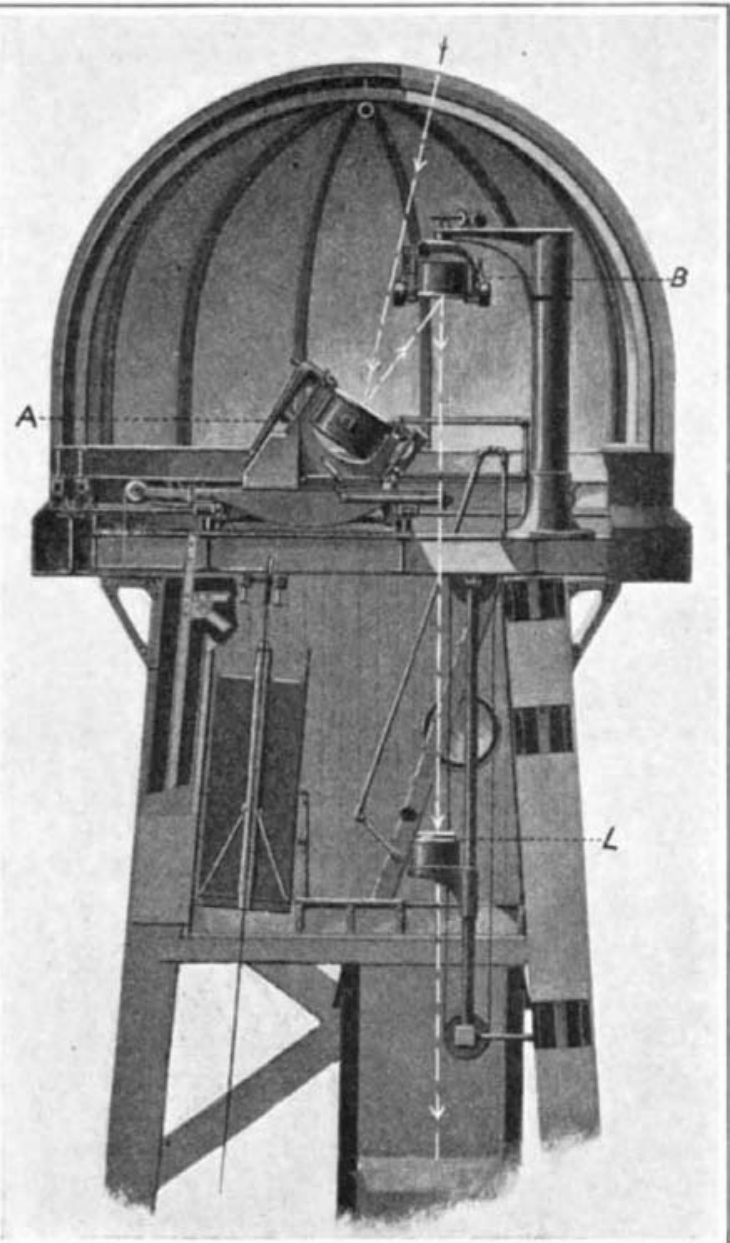

Fig. 1. - Course of the light in the tower telescope.

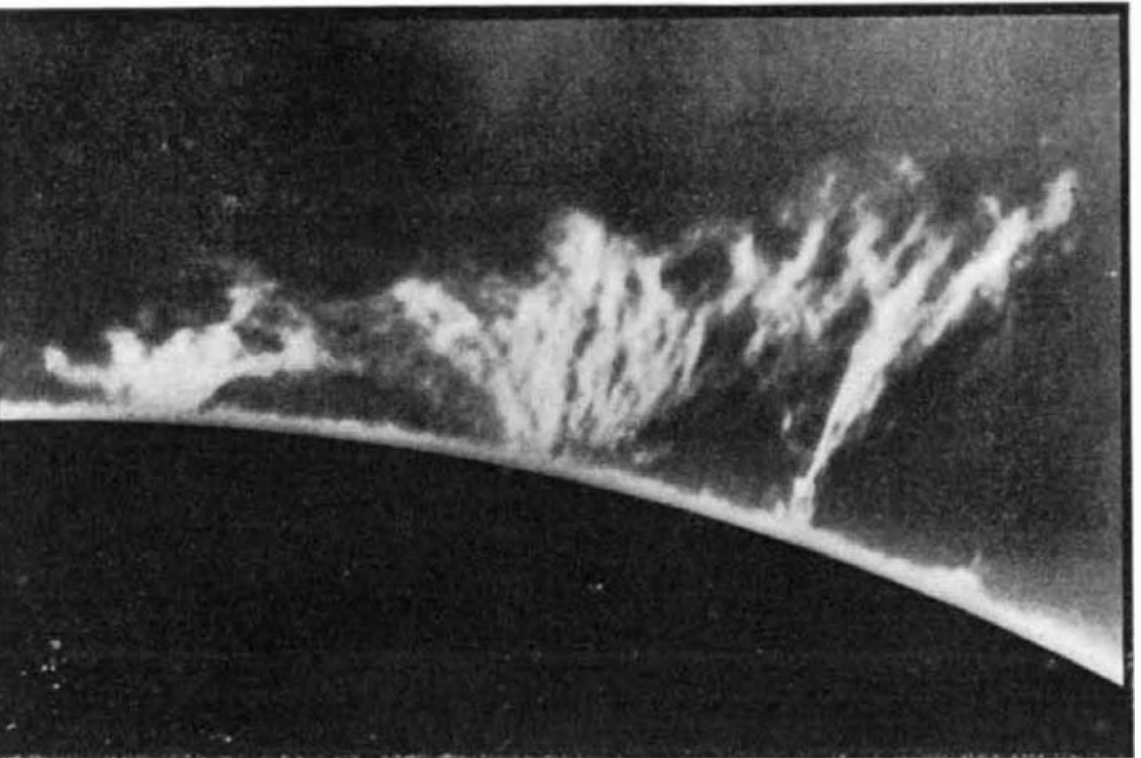

Fig. 3.-Great hydrogen prominence, photographed on August 21st, 1909, THE GREAT TOWER TELESCOPE OF THE MT. WILSON SOLAR OBSERVATORY trolled electrically from the observing room at the base of the tower. This corrects for east and west errors. North and south deviations can be corrected by means of a motor geared to the mirror $B$ and also controlled by the observer below.

After leaving the mirror $B$ the beam passes through a lens $L$ of 12 inches aperture and is brought to a focus at $F$ (Fig. 2) 150 feet below. To permit accurate focusing the lens can be moved vertically. This, too, is accomplished by means of an electric motor controlled by the observer. For some investigations the large solar i m ag e ( 17 inches in diameter) formed by the lens $L$ may not be desirable. When this is
the case lenses of 60 or 30 feet focus can be used, being supported at these respective heights a bove the point $F$.

The apparatus thus far described has been designed t, o produce the best possible best possible image of the sun in th serving room. We now come $\iota 0$ the $\mathrm{two*}$ instruments which are used for the investigations proper. The one is a spectrograph and trograph and the other is a spectroheliograph. The first is used to study the spectrum of the sun. It shows what elements are present in the solar a t mosphere; and by means of a small adof apparatus, can also be used to de-

length. On account of this great length it would be very troublesome to mount it so that it could be moved to follow the sun across the sky. It is therefore fixed in a vertical position,* the usual tube for supporting the lens being replaced by the frame of the tower. But now that the telescope is fixed some way must be found to direct the beam of light into it and at the same time allow for the motion of the sun. The devicet adopted consists of

* The longest telescope at present that can be moved in this manner is the great 40-inch refractor of the Yerkes Observatory which has a focal length of 63 feet. Fixed telescopes have been wed for many years at various observatorles but they have

+ Attention should be called to the fact that the reflection occurs directly from the silvered surface, the light not penetrating the glass at all. The silver film thus exposed tarnishes such a way that its axis of rotation is parallel to the earth's axis and lies in the plane of the reflecting surface. The rotation about its axis is produced by means of a driving clock similar to that of an equatorial telescope. The mirror rotates at such a rate that the reflected beam has a constant direction. In this case it is upward toward a second plane mirror $B$, of 15 inches aperture, so placed as to reflect the beam vertically downward.

A unique device has been adopted to make these mirrors extremely rigid so that they will not be sensibly distorted by the sun. This consists in making them very thick. Thus the coelostat mirror is 13 inches and the other 11 inches in thickness. This device has proved so efficient that exposure to the sun for hours at a time pro-

Any errors in the rate of the driving clock can be corrected by means of a differential gear and motor conduces no serious distortion. termine the rotation period of our great luminary, ete. The second instrument, the spectroheliograph, is used to determine the distribution of the various gases and vapors in the atmosphere of the sun. Thus it is possible by means of it to isolate the light coming to us from the hydrogen in this atmote the light coming to us from the We thus obtain a picture showing the sun as if it consisted of hydrogen only. Similarly it is possible to get pictures with the light of calcium vapor alone, or iron, etc As changes are continually going on, a series of photographs che movements of hydrogen or calcium. In Fig. 3 an enormous hydrogen cloud or prominence is shown at the edge of the sun. $\dagger$ This formed and disappeared in about 48 * There is in reality but one combination instrument but for our purpose it is best to consider this as two separate instruments. graph of the Snow horizontal telescope 
hours. Similar formations have been known to come and go in one-tenth the time. The tremendous velocities and masses involved can hardly be appreciated, for one inch in the figure corresponds to nearly 50,000 miles at the surface of the sun.

The two instruments mentioned are each 80 feet in length and placed vertically in a well of the same depth. These instruments project upward into the observin room about 3 feet to the level $F$ (Fig. 2) at which the image of the sun is formed. The light enters either instrument at this point and passes down its length to the bottom of the well. It is there analyzed by either prism or grating and then reflected back a little to the side of $F$ where the photographic plate is located. Plates up to 36 where the photographic plate
inches in length may be used.

Now that we have considered briefly the arrangemen and use of the optical parts, we are in a better position to appreciate the general construction of the tower, etc One of the difficulties with all telescopes used for refined work is their liability to be shaken by the wind. To provide against this a very ingenious plan was adopted. The tower is double, or rather, there are two complete towers, one within the other, each with its own set of piers and nowhere touching. This can be seen best in Fig. 4, where two complete sections of the light inner tower are in place while the outer tower, which is to in close the inner, member by member, has just bee started, only the lowest horizontal and first vertical members being in position. Each member of the outer tower is of box construction, within which is the corresponding member of the inner tower. All the optical parts above the observing room are supported by the inner tower while the outer carries the dome and completley shields the other from the wind.

The buge concrete piers for the outer tower, eight in $\mathrm{n}$ imber, are in part shown in Fig. 4 . The relation of the piers of the two towers is best seen in Fig. 2, the pier for the inner tower being the ones extending just to the surface of the ground.

The erection of this double tower afforded considerable difficulty, as it was quite different from the ordinary structural steel job. The general scheme, however, can
be seen from the illustrations. The men worked on platbe seen from the illustrations. The men worked on plat-
forms suspended on the outside. The steel was put into place by a gin pole and the usual hoisting engine. When a section of the inner structure was in place each member was inclosed by the corresponding box-like member of the outer. Great care was necessary that neither was in contact with the other at any point. A clearance of 3 inches between the two permits considerable vibration of the outer tower without affecting the inner.

The dome is not of the usual type. It consists of two half-domes, one slightly larger than the other. When closed the two halves fit snugly together and afford good protection from the weather. Upon opening, the smalle section can be rotated until it is wholly within the other thus leaving one side entirely open. In Fig. 5 it is open to its fullest extent. It will be recognized that this dome has about the same relation to the tower telescope that the lens cap has to an instrument of the ordinary type.

Down the center of the tower can be seen a square tube made of sheet iron. About this are placed canvas louvres to protect it from direct sunlight. By this means troublesome radiation effects are eliminated in the air column through which the beam of light passes after leaving the lens.

The observing room is shown in Fig. 2. It is at the base of the tower and directly over the 80 -ioot well There is a photographic dark room in connection with it. The entire structure is of reinforced concrete.

The height of the tower from the ground level to the floor of the dome is 160 feet. The dome adds 13 feet floor of the dome is 160 feet. The dome adds 13 feet
more, so that the total height is 173 feet. The weight more, so that the total height is 173 feet. The weight
of the steel used in the construction is 150 tons. The of the steel used in the construction is 150 tons. The
eight concrete piers for the outer tower weigh about 70 tons each, while the four piers for the inner tower each weigh 19 tons.

The well, which is 10 feet in diameter, was sunk into the rock before the tower was erected. It is lined with an 8-inch concrete wall. A spiral stairway, as shown in Fig. 2, provides an easy way to reach the optical parts at the bottom of the well whenever these need adjustat the bottom of the well whenever these need adjust-
ment. The well has a special advantage in that it has ment. The well has a special advantage in that it has practically the same temperature throughout the year.
This constancy of temperature is of prime importance This constancy of temperature is of prime importance
for the prism or grating in the spectrograph or spectroheliograph. Very slight changes of temperature during an exposure which may last several hours are fatal to work of high precision.

The great height of the tower has one advantage not yet mentioned. Anyone looking along a hot street has undoubtedly noticed how an object near the ground seems to be trembling owing to the intermingling of the unequally heated air currents. An object at some disunequally heated air currents. An object at some dis-
tance above the street does not appear to tremb'e anything like as much. Hence if we increase the elevation above the earth at which the beam of light is received by the lens and then carefully shield this beam by means of the tube of sheet metal, it is possible to get a much steadier image of the sun than if the beam were received near the ground.
An elevator run by an elestric motor is used to make the ascent of the tower for opening the dome and setting the mirrors before beginning observations. A ladder is also provided should the elevator be temporarily out of commission, but it goes without saying that the elevator is the more popular of the two.

Electric motors are used to control the movements of the various instruments, the switches being as far as possible directly under the observer's hand. Most of the motors are of the reversible type, as double motions are usually necessary. Eighteen motors are required for the various purposes.

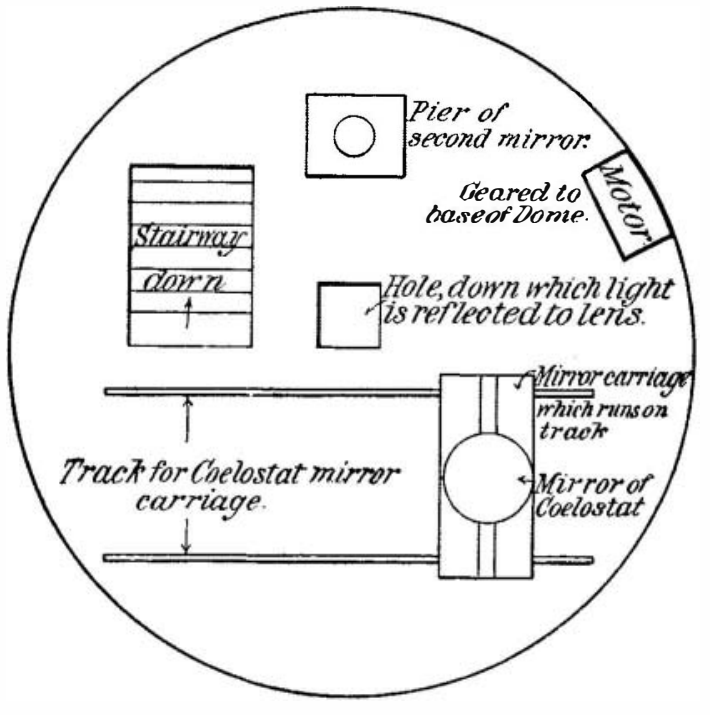

Fig. 6. -Top plan view of the tower and its apparatus.

The great instrument thus briefly described has just been completed. In the hands of Dr. Hale and his coworkers it will undoubtedly greatly aid in solving many of the troublesome problems in solar physics. Acknowledgments are due to Mr. Ellerman and Mr.
Messer of the observatory staff for the excellent photoMesser of the observatory staff for
graphs used to illustrate this article.

\section{Crop Improvement: A Problem in Increasing} Our National Efficiency

\section{By C. M. Carroll}

IT is generally conceded by those who know, that science is twenty-five years in advance of its practical also to the science of farming, which is our primary base of supply. Since the superstructure of commerce is builded upon a foundation of agriculture, commercial development is the logical sequence of agricultural development. Soil, therefore, it seems, always was, and never has ceased to be, the world's principal asset. No one has even attempted to dispute it. Since commerce is simply an intercbange of commodities which are produced from the soil, business men cannot say, "Why should we bother our heads about the crops? Let the farmers take care of their own business and we will take care of ours."

"Mind your own business" is an excellent motto, but, so few of us really know what is our own business. Agriculture is so interwoven with the business of us all that it is impossible to find the line of cleavage where one man can say, "This is my business, let me alone." We are all of us convinced that it is immediately necessary to add to our national wealth by getting more out of the soil. Farming is everybody's business, and woe to the man who says that he is not concerned in the business of farming. We have been carrving no grain surplus, and a single crop failure would put us on almost a famine basis. The United States, from year to year, is becoming less considered in the feeding of other nations, and we are rapidly drifting to the point where the balance of trade will be permanently against us. How are we going to regain the money spent by our tourists abroad, the interest on our bonds and the vast sums which are expended for diamonds and luxuries from every part of the world?

When we look at the ten-acre plots of Europe and behold a larger yield than from a forty-acre American field, we feel that our millions of farmers are in reality no farmers at all; and with the exception of here and there a man who is tilling the soil with thrift and intelligence, the great majority are still robbing the land, and getting less than half of the crop.

In 1910 there were two hundred million acres of wheat, corn and oats harvested in the United States. Our agricultural scientists tell us that we can increase any crop from four to ten bushels per acre in a single season by seed selection and proper cultural methods.

In spite of the excellent and energetic work of the United States and State Departments of Agriculture the agricultural colleges and extension department farmers' institutes, and a thousand other things which are being preached by the agricultural press, the unpleasant fact still remains that twenty years ago the United States raised more than six hundred million bushels of wheat which is about the same amount raised in 1911, while our population has increased nearly thirty million souls.

Notwithstanding our enormous activities, the average yield of corn per acre is slightly more than thirty-four bushels. Prize corn growers have demonstrated that it is possible to grow two hundred and twenty-five bushels to the acre. The price of flax seed is soaring all out of proportion, and barley is selling for $\$ 1.25$ per bushel, for a very poor grade at that. The cost of living is not so high in this country, but it will be higher in the near future if the present tendencies continue. It is common knowledge that vast areas of land in the original thirteen States now lie abandoned. Many farms of the Middle West States are now undergoing rapid soil depletion as a result of careless farming. Quoted from eminent authority, "The American farmer has learned well the art of agriculture in the hard school of experience, but the science of agriculture is almost unknown to him; and unknown not only to the farmers and land owners, but also unknown to the statesmen, unknown to the local public officials, unknown to the teachers of the oommon schools, and unknown to the preachers, to the merchants, to the grain dealers and to the bankers."

So it is evident that preaching and the printing of bulletins are not altogether satisfactory.

True co-operation. means the greatest good to the greatest number, and upon this basis Bert Ball, secretary of the Crop Improvement Committee of the Council of Grain Exchanges of America, is making an effort to unify and harmonize all of the interests, including the manufacturers of agricultural implements, fertilizers, grain and elevator companies, cereal manufacturers, chemical manufacturers, railroads, bankers, and all other business interests in a National crop improvement plan to co-operate with the U. S. Department of Agriculture and the various branches of the extension department of the State agricultural colleges. Individual effort at cross purposes will not accomplish satisfactory results. The plan covers the development of each county through an amalgamation of commercial, educational, transportation and agricultural interests. It advocates the establishment of trained agriculturists in each of the counties of all of the agricultural States in connection with the United States Bureau of Farm Management, State agricultural colleges, State commercial associations and local commercial clubs.

The National fund for this purpose is now being raised in order to offer $\$ 1,000$ or more to each county in each State, and State commercial organizations are ready to form State crop improvement associations to raise a like amount to that offered to each county from the National organization. This fund has been started with one million dollars by Messrs. Sears, Roebuck \& Co., of Chicago, who have set aside the sum $\$ 1,000$, to be given to each of 1,000 counties in every State which will raise a fund locally, sufficient to employ a permanent county agriculturist and farm demonstrator.

The Government Bureau of Farm Management also has a fund, and offers to bear from one third to one half of the expense of this Farm Bureau in any county the plans of which are acceptable as soon as its funds become available for this year. This will add approximately another $\$ 1,000$ to each county ready to raise its own fund.

While there are scarcely any two counties operating under exactly the same plan, the following is the one recommended by the Crop Improvement Committee.

First: That a joint meeting be called by the commercial organization or organizations, to which there will be invited editors, railroad men, road commissioners, superintendents of county schools, superintendent of the county farm, the county supervisors (commissioners of county court, as the case may be), bankers, millers, manufacturers, grain buyers, officers of all farmers and breeders' organizations, the leading farmers and land owners in each township. This meeting to be conducted by a member of the Crop Improvement Committee of the Council of Grain Exchanges, explaining the nature of the movement.

Second: That a committee on crop improvement and county development be appointed by the rresident of the commercial club: that the members of this committee shall act ex-officio as chairman of the sub-committees on ways and means, membership, grain, good roads, marketing, agriculture in the schools, dair inspection, landlord and tenant, etc.

Third: That a special section be added to the constitution and by-laws of the commercial club providing for an agricultural membership at a nominal fee per year, in order to obtain a widespread special membership, placing the farmer upon a business basis, establishing him as a business man among business men.

Fourth: That the sum to be raised in each county should equal annually one cent per acre of all the tillable land in the county, or a minimum of $\$ 100$ to be subscribed by farmers, landowners, elevators, countr merchants, professional men, blacksmiths, hotels, etc. in each township.

(Section Four, like the whole plan, is elastic, and may be changed to fit local conditions.) 